\title{
Improved direct torque control of induction motor with dither injection
}

\author{
R K BEHERA and S P DAS \\ Department of Electrical Engineering, Indian Institute of Technology, \\ Kanpur 208016 \\ e-mail: ranjanee@iitk.ac.in; spdas@iitk.ac.in
}

\begin{abstract}
In this paper, a three-level inverter-fed induction motor drive operating under Direct Torque Control (DTC) is presented. A triangular wave is used as dither signal of minute amplitude (for torque hysteresis band and flux hysteresis band respectively) in the error block. This method minimizes flux and torque ripple in a three-level inverter fed induction motor drive while the dynamic performance is not affected. The optimal value of dither frequency and magnitude is found out under free running condition. The proposed technique reduces torque ripple by $60 \%$ (peak to peak) compared to the case without dither injection, results in low acoustic noise and increases the switching frequency of the inverter. A laboratory prototype of the drive system has been developed and the simulation and experimental results are reported.
\end{abstract}

Keywords. Direct torque control; dither injection; induction motor drives; three-level converter.

\section{Introduction}

Direct Torque Control (DTC) is a well-known control scheme for induction motor (IM) drives (Behera \& Das 2006). Three-phase three-level Neutral Point Clamped (NPC) inverter is used for driving the induction motor in high power applications. Three-level NPC converter-fed direct torque controlled induction motor drive ensures fast dynamic control of the drive even under the low switching frequency operation. The source of delay is Hall Effect sensor and data acquisition system. Thus, the presence of delays in measurement and computation leads to low switching frequency resulting in increased torque and flux ripples. In addition, the drive produces acoustic noise. The injection of dither signals of suitable magnitudes and frequencies in the torque and flux errors can reduce the torque ripples and acoustic noise in the drive. Mainly dithering is required to improve the switching frequency of inverter.

It has been known that injection of a high frequency dither signal will in certain instances upgrade the performance of a nonlinear system (Gelb \& Vander Veido 1968; Kinkaid et al 2002; Cook 1986). The frequency of this signal is usually chosen considerably above the cutoff frequency of the system so that its presence cannot be detected in the output. The method is robust to measurement noise as instantaneous injection of high frequency signal stabilizes 
the system in which the system parameters are not exactly known and unalterable (Elgerd 1967). In Iannelli \& Vasca (2004), Iannelli et al (2003), dither is used for reducing chattering in the sliding mode and relay based controller is presented. In Zames \& Shneydor (1976), effect of dither in nonlinear system and its stabilization is presented. In this paper, a triangular dither signal is injected of minute amplitude (5\% of rated torque and 5\% of reference flux as hysteresis band in torque control and flux control loops respectively) in the error block. The optimal value of dither frequency and magnitude is found out under free running condition. This technique gives minimum torque ripple, low acoustic noise and increases the switching frequency of the inverter. A laboratory prototype of the drive system has been developed. The simulation and experimental results are reported to validate the control scheme.

\section{Direct torque control algorithm}

The generic DTC scheme for a three-level VSI fed IM drive is shown in figure 1. Three-level inverter voltage vectors are shown in figure 2. According to the block diagram (figure 1), the scheme includes two hysteresis band controllers. DTC is basically a stator flux oriented scheme and is based on the limit cycle control of both stator flux and torque. The stator flux controller imposes the time duration of the active voltage vectors, which move the stator flux along the reference trajectory. The torque controller determines the time duration of the zero voltage vectors, which keep the motor torque in the defined hysteresis tolerance band. At every sampling time the voltage vector selection block chooses the inverter switching state, which reduces the instantaneous flux and torque errors.

Five-level torque comparator as shown in figure 3 and two-level flux comparator are employed for three-level inverter based DTC (Behera \& Das 2006).

Positive torque is applied for acceleration and negative torque is applied for retardation. When the controlled torque reaches the positive lower hysteresis band, a full voltage vector is replaced with a half voltage vector. If torque increases beyond the positive upper torque band, the zero voltage vector is applied to decrease the developed torque. For reverse rotation, in the same way, retarding voltage vectors are applied. The resulting look-up table is shown in table 1 (Behera \& Das 2006).

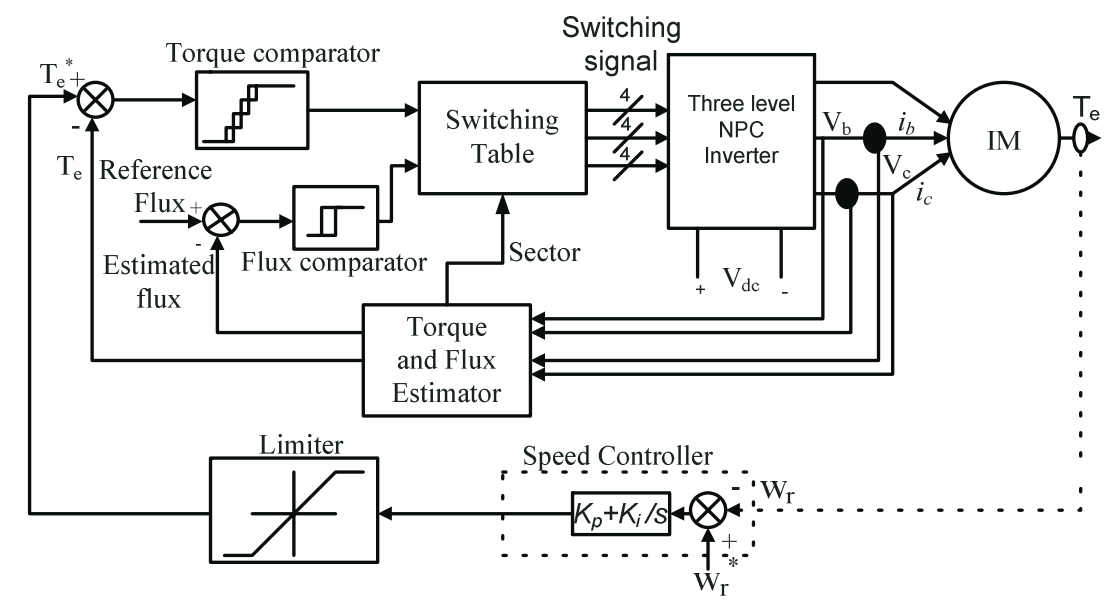

Figure 1. Block diagram of three-level inverter-fed DTC induction motor drive. 


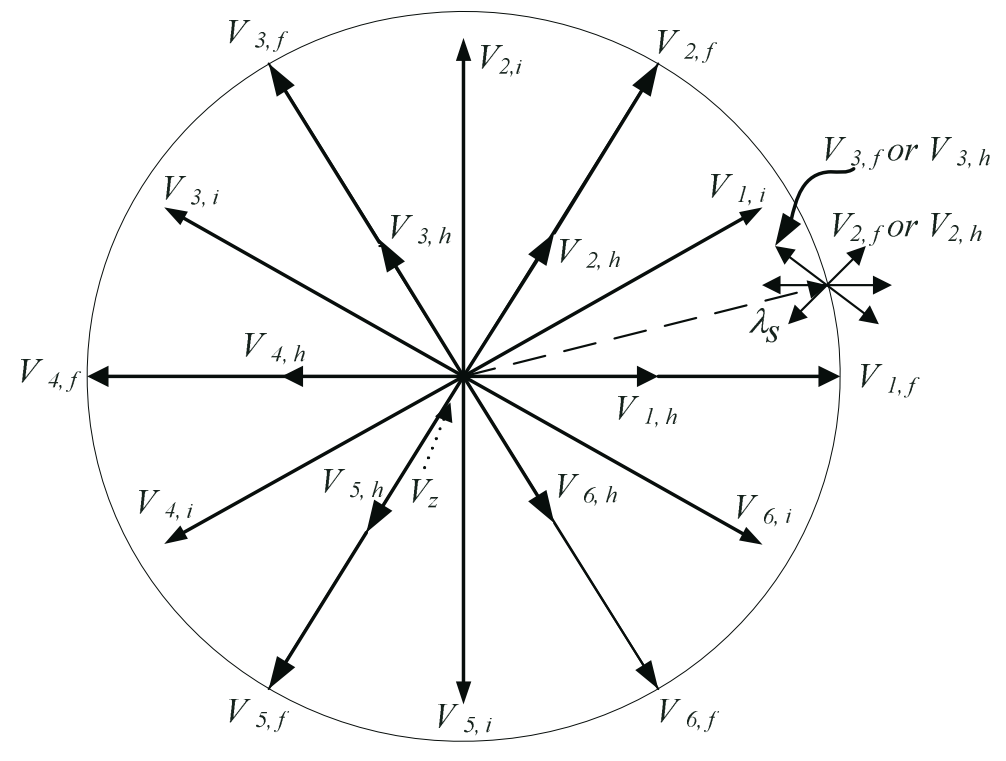

Figure 2. Output voltage vector of three-level VSI.
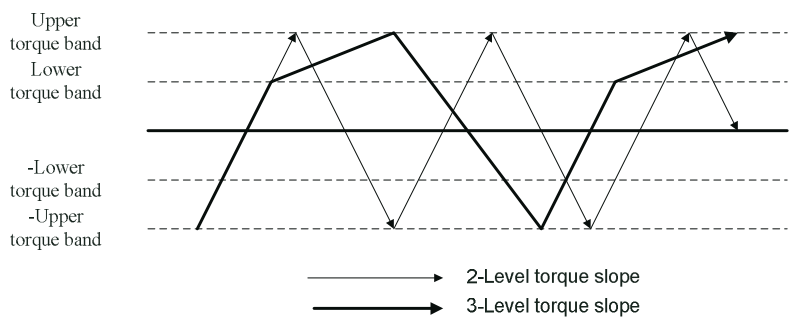

Figure 3. Torque slope pattern of three-level inverter.

Due to introduction of delay in a practical system, it is found that the switching frequencies of the power switches are reduced. An analytical study has been carried out for switching frequency under different hysteresis band conditions and the analysis is shown in figure 4. Further, digital implementation of hysteresis controllers for torque and flux introduces delay in the program execution. This leads to increase in current, torque and flux ripples, and

Table 1. Switching look-up table.

\begin{tabular}{lcccc} 
& & \multicolumn{3}{c}{ Torque } \\
\cline { 3 - 5 }$\lambda_{s}$ is sector $k$ & $\uparrow$ & $\Uparrow$ & $\downarrow$ \\
\hline \multirow{2}{*}{ Flux } & $\uparrow$ & $V_{k+1, h}$ & $V_{k+1, f}$ & $V_{z}$ \\
& $\downarrow$ & $V_{k+2, h}$ & $V_{k+2, f}$ & $V_{z}$ \\
\hline
\end{tabular}

$\uparrow$ increase, $\Uparrow$ more increase and $\downarrow$ decrease 


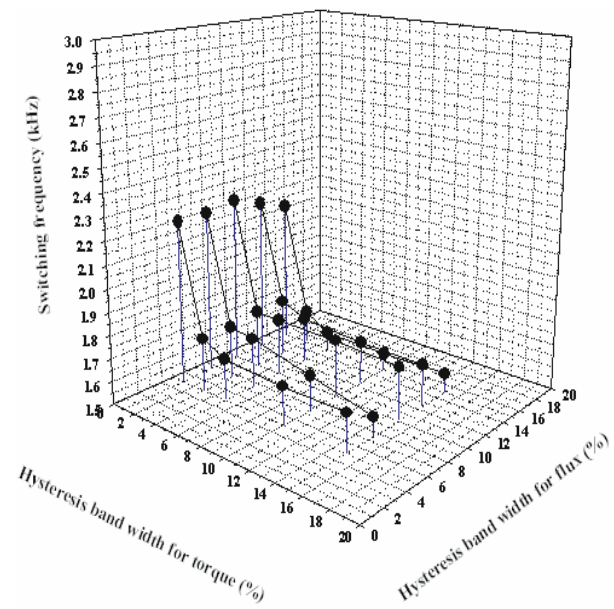

(a)

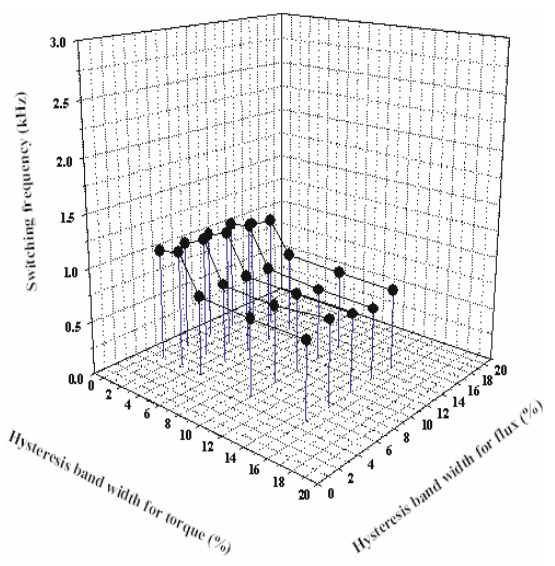

(b)

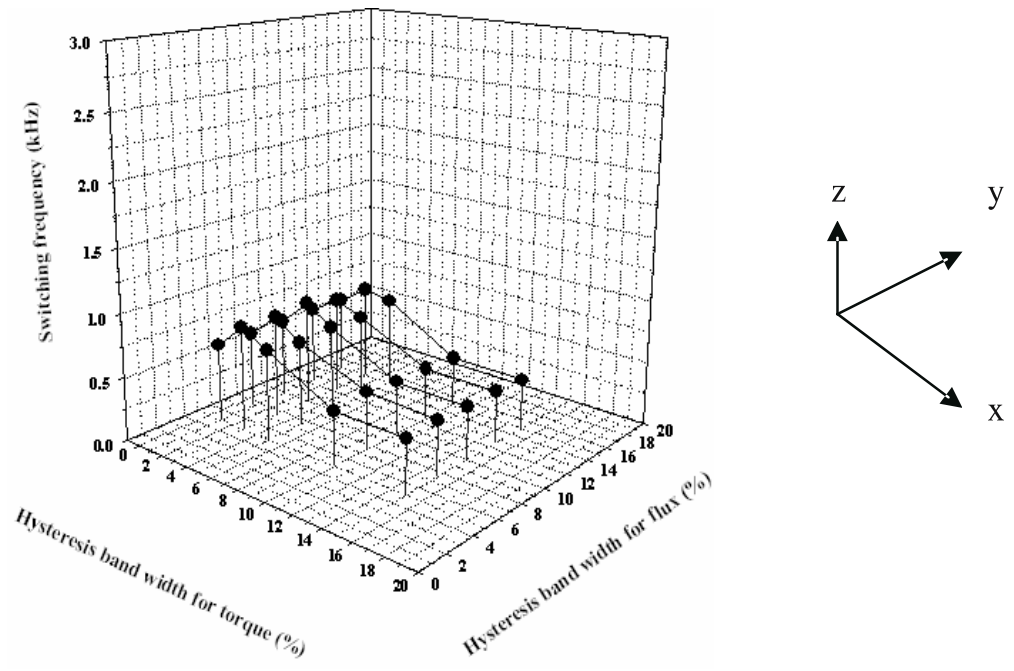

(c)

Figure 4. Analytical results of conventional DTC. $z$-axis: Switching frequency in kHz. $x$-axis: Torque hysteresis band in \%. y-axis: Flux hysteresis band in \%. (a) No delay in the feedback loops; (b) $10 \mu \mathrm{s}$ delay in the feedback loops; (c) $20 \mu$ s delay in the feedback loops.

gives rise to acoustic noise. The developed torque is not constrained within the error band of the hysteresis controller (Ambrozic et al 2004). To overcome the difficulty as mentioned, a compensating technique is developed, which is based on the injection of high frequency triangular dither signal.

The inverter switching frequency is analysed for zero time delay, $10 \mu \mathrm{s}$ and $20 \mu \mathrm{s}$ in the estimator block in the feedback path. Figures $4 \mathrm{a}-\mathrm{c}$ show the simulation results of the average switching frequency against the torque and flux hysteresis band width when the motor is operating under free running condition with a speed of $955 \mathrm{rpm}$. In these figures, the hysteresis bandwidths are normalized with respect to the rated stator flux amplitude and rated torque 
respectively. From the above figures, it is confirmed that the inverter switching frequency mainly depends on torque hysteresis band width. It is observed that the switching frequency cannot be raised, although hysteresis bandwidth for torque control is reduced to a sufficiently low value (Ambrozic et al 2004). This is due to band constrain of the DTC drive. When $10 \mu$ s delay is introduced in the feedback path, the upper limit of switching frequency is nearly $1.1 \mathrm{kHz}$. For a delay of $20 \mu \mathrm{s}$ the switching frequency becomes $0.8 \mathrm{kHz}$. The switching frequency, however, is somewhat decreased when the hysteresis bandwidths are excessively diminished. This is because of abnormal resonant oscillations between the flux and torque ripples and the dither signals. As the hysteresis bandwidths are decreased, the gradient of the flux error and the torque error with respect to time becomes closer to that of the dither signals. This causes the inappropriate switching in the hysteresis elements, which results in the non-optimized PWM pattern (Noguchi et al 1999).

\section{Analytical study of dither signal injection}

Dither injection is required to reduce torque and flux ripple of the conventional DTC drive as mentioned in $\S 2$ in the presence of measurement and computational delays. The sensors used for the present system are (LV-25 P) for voltage measurement and (LA 55-P) for current measurement respectively. The delays associated with these sensors are due to sensor response time. A/D conversion time is $2 \mu$ s for multiplexed channel and $800 \mathrm{~ns}$ for parallel channel. Execution time of the estimator is around $1.66 \mu \mathrm{s}$. So average delay associated with the DTC drive is around $7.5 \mu \mathrm{s}$. The presence of delay leads to low switching inverter frequency which is corrected by dither injection.

Figures $5 \mathrm{a}-\mathrm{b}$ show the schematic diagram of the dither injected system, where triangular waves are employed as the dither signals in the error blocks. The dither signal is superimposed on the torque and flux error loop, so that the overall system performance can be improved. The frequency of the triangular waves should be approximately $30 \mathrm{kHz}$ to keep the three-level NPC inverter switching frequency more than $5 \mathrm{kHz}$ and their amplitudes should be small compared to the hysteresis band for the flux and torque error band. However, it is not necessary to fix
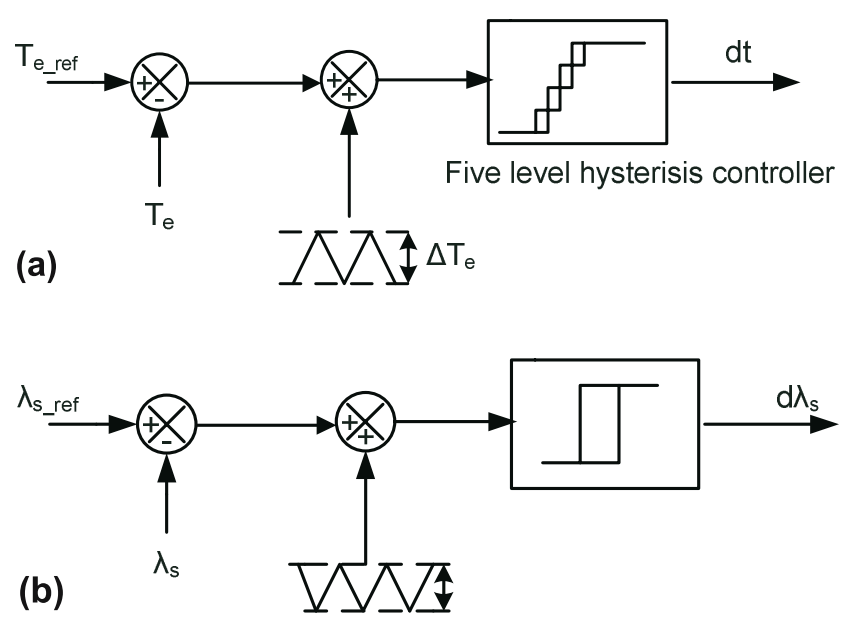

Figure 5. (a) Injection of triangular dither in torque control loop: (b) Injection of triangular dither in flux control loop. 
specifically the relative phase between the two dither signals because the frequency spectra of the current and the acoustic noise of the motor can be dispersed (Noguchi et al 1999).

The inverter switching frequency is a function of the hysteresis band for the torque control. Since the relay operation of the torque control is performed alternatively between one of the zero-voltage vectors and one of the non zero-voltage vectors, only one inverter leg of the three phases changes its own switching state at every switching time of the hysteresis element. This implies that the averaged inverter switching frequency can be approximated to one-sixth of the dither frequency for the three-level NPC inverter-fed induction motor drive.

In the conventional switching algorithm, applied voltage vector can be selected based on the condition of the flux and torque error command. But due to inherent delay in the feedback system, the torque and flux errors will cross the boundary of flux and torque error band limits. This phenomenon is clearly explained in Ambrozic et al (2004).

Using the present method, the flux and torque ripples can be suppressed less than the hysteresis band limit, and the switching cycles of the hysteresis elements are increased accordingly. The hysteresis bands of the relay elements act inherently as insensitive bands, but, owing to the superposition of the triangular waves on the errors, the hysteresis elements can change their switching states, regardless of the minute error variations. It should be noted that the dynamic response of the original system is not degraded.

\section{Analysis and comparison of results}

The simulation is carried out in Matlab-Simulink and typical results are reported here. Figures $6-8$ show the computer simulation results that have been obtained by driving the induction motor at $1000 \mathrm{rpm}$ under the free running condition. The rated values and the nominal parameters of the motor are shown in table 2. This simulation result is obtained under rated flux condition.

All simulations have been carried out without and with triangular dither injections for comparison. Triangular dither is injected here having a frequency of $30 \mathrm{kHz}$. Amplitude of dither signal in torque control loop is $5 \%$ of rated torque and the amplitude dither signal in flux control loop is $5 \%$ of reference flux. Both the dither signals are opposite to each other in phase to minimize the acoustic noise (Kinkaid et al 2002).

Table 2. Induction motor drive ratings and parameters.

\begin{tabular}{ll}
\multicolumn{2}{c}{ (Referred to stator) } \\
\hline DC link capacitor $C_{1}=C_{2}$ & $2200 \mu \mathrm{F}$ \\
Power & $5 \mathrm{hp}$ \\
Voltage $(L-L)$ & $415 \mathrm{~V}$ \\
Current & $7.6 \mathrm{~A}$ \\
Frequency & $50 \mathrm{~Hz}$ \\
Rated torque & $24.5 \mathrm{~N}-\mathrm{m}$ \\
Speed & $1440 \mathrm{rpm}$ \\
Stator resistance $\left(R_{s}\right)$ & $2 \cdot 177 \Omega$ \\
Rotor resistance $\left(R_{r}\right)$ & $1 \cdot 275 \Omega$ \\
Stator leakage inductance $\left(L_{l s}\right)$ & $0 \cdot 0081 \mathrm{H}$ \\
Rotor leakage inductance $\left(L_{l s}\right)$ & $0 \cdot 0081 \mathrm{H}$ \\
Mutual inductance between stator and rotor $\left(L_{m}\right)$ & $0 \cdot 1683 \mathrm{H}$
\end{tabular}



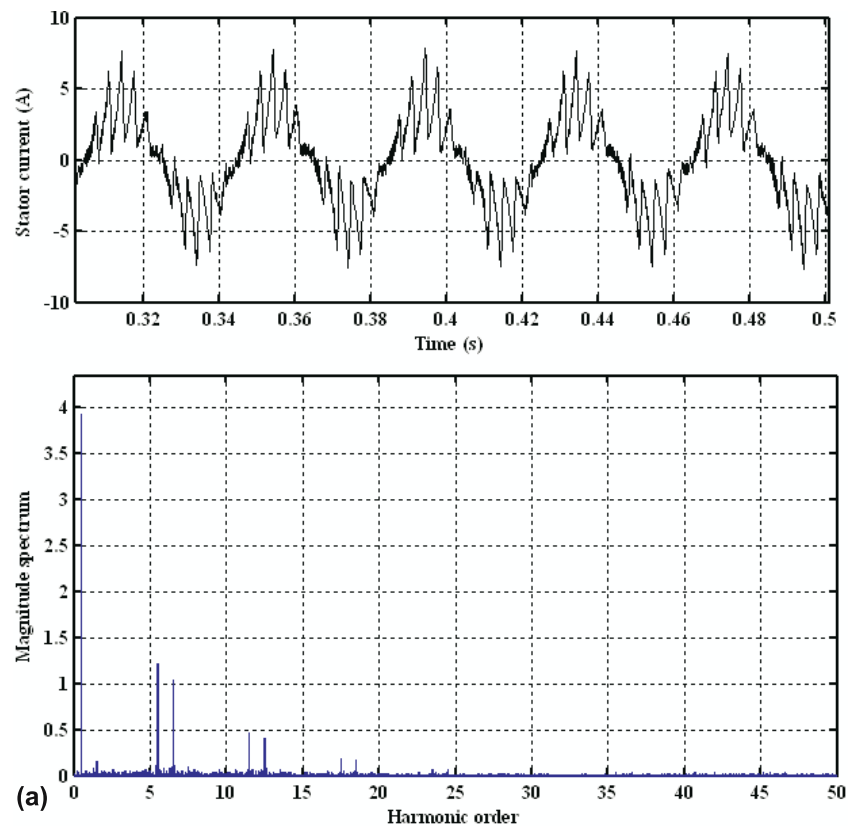

Figure 6a. Steady state stator current and harmonic spectrum without dither injection.

Figures $6 \mathrm{a}$ and $\mathrm{b}$ show the three-phase steady state stator current and its harmonic spectrum without dither and with dither injection respectively. From the simulation result, it is confirmed that the current ripple is reduced due to dither injection in the flux loop. The harmonic
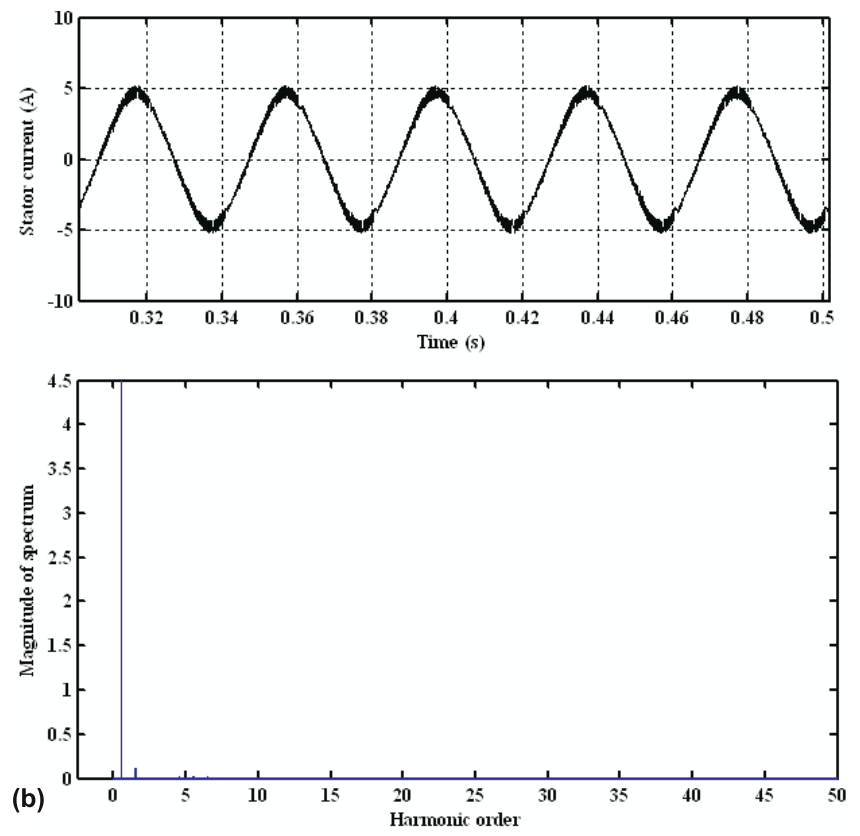

Figure 6b. Steady state stator current and harmonic spectrum with dither injection. 


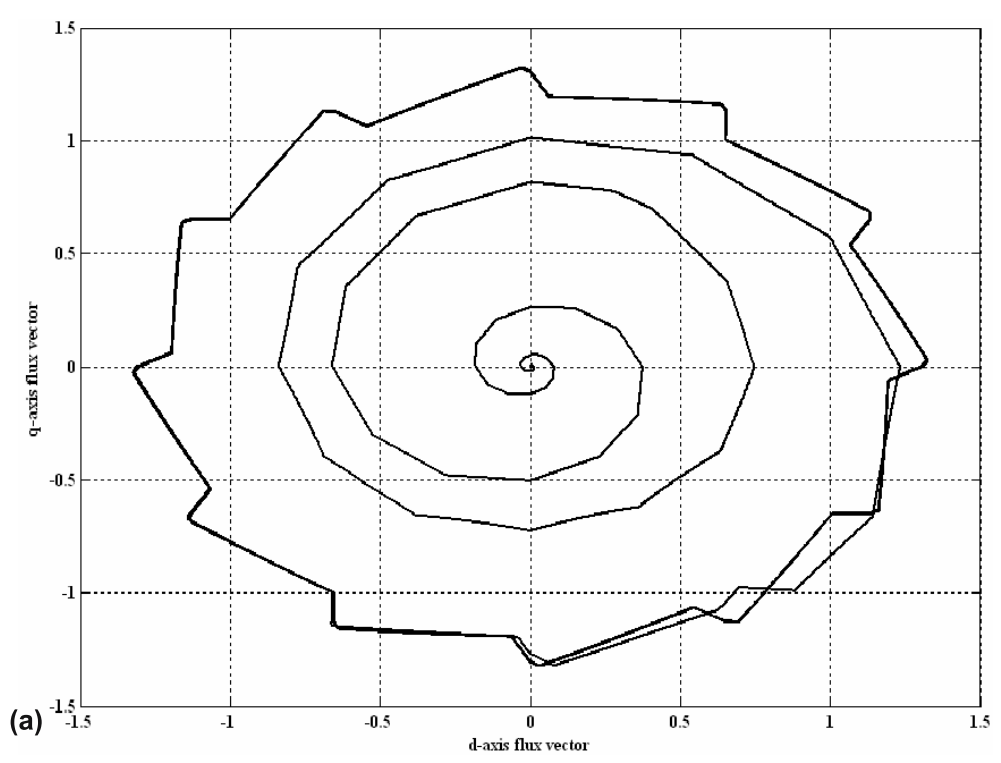

Figure 7a. Stator flux trajectory without dither injection.

spectrum also improved. Figure $7 \mathrm{a}$ and $\mathrm{b}$ show the stator flux trajectory without and with dither injection respectively. A $7.5 \mu$ s delay in the feedback path is considered. This shows that the flux error band crosses the boundary of flux error limit without dither injection. This increases flux ripple so also current ripple. A smoother flux trajectory is achieved by injection of triangular dither.

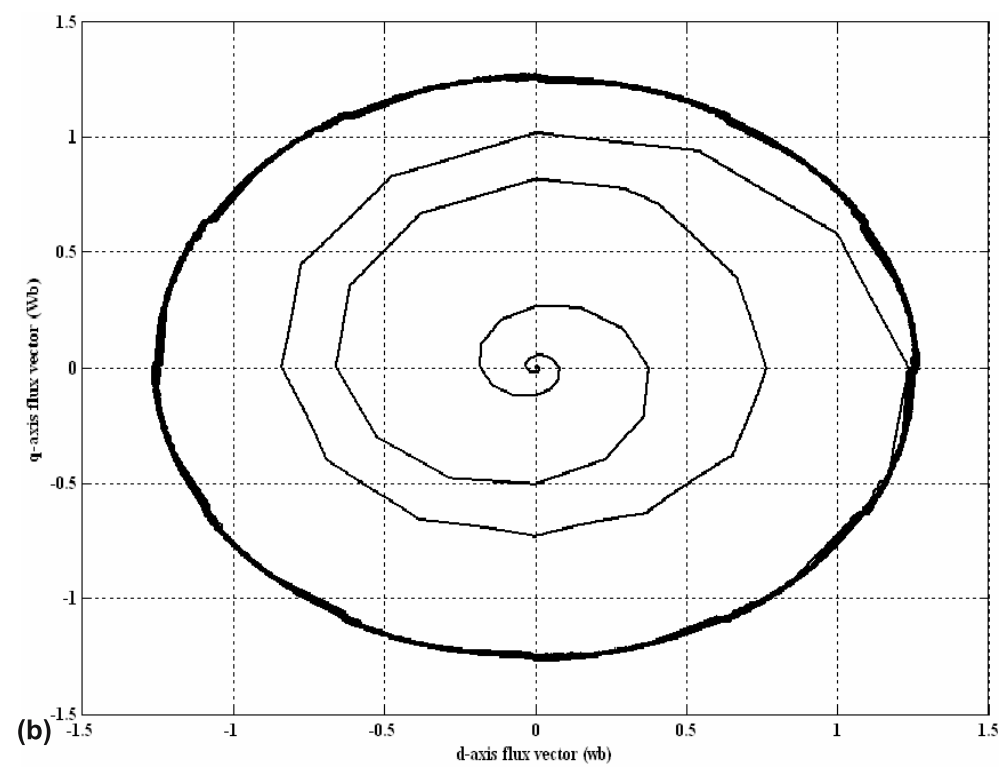

Figure 7b. Stator flux trajectory with dither injection. 


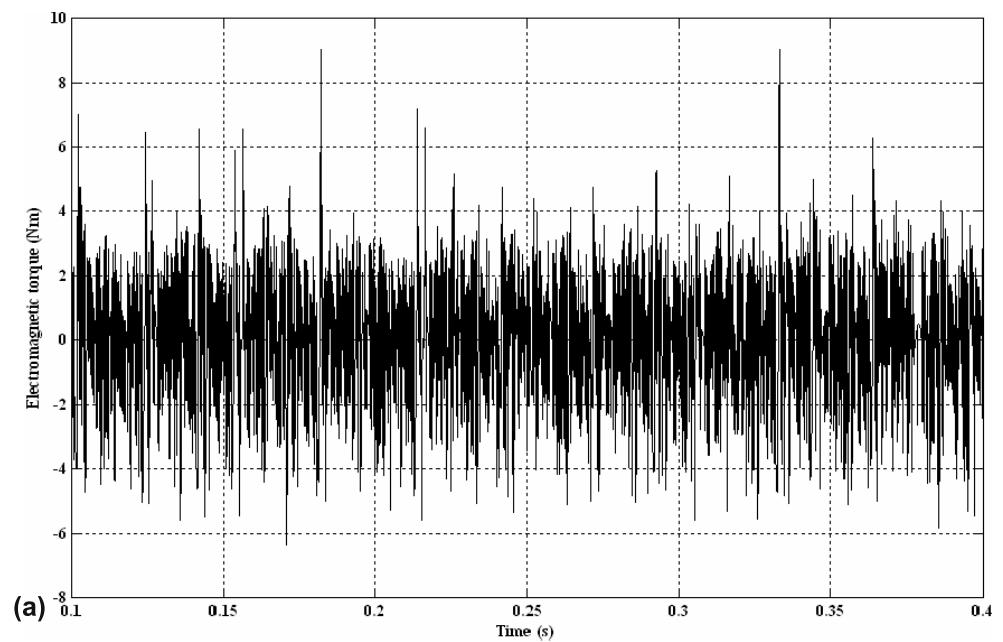

Figure 8a. Electromagnetic torque without dither injection.

Figure 8 shows the simulation results of the developed electromagnetic torque with and without dither injections. According to the figure, when dithering is applied to the system the peak to peak torque ripple is reduced by $60 \%$ compared to that of the system when no dither is injected. To show the effectiveness of the triangular dither injection on inverter switching frequency, computer simulation study has also been carried out. Figures $9 \mathrm{a}$ and $\mathrm{b}$ show the instantaneous switching frequency without and with dither injections. It is clearly seen that inverter switching frequency increases to an average switching frequency of $2 \cdot 2 \mathrm{kHz}$. This leads to improvement in current and torque ripple.

The three-phase three-level inverter consists of six dual IGBT modules (SEMIKRON, SKM 75GB128D, $1200 \mathrm{~V}, 100 \mathrm{~A})$, i.e. two IGBTs per module is used in this topology. Three

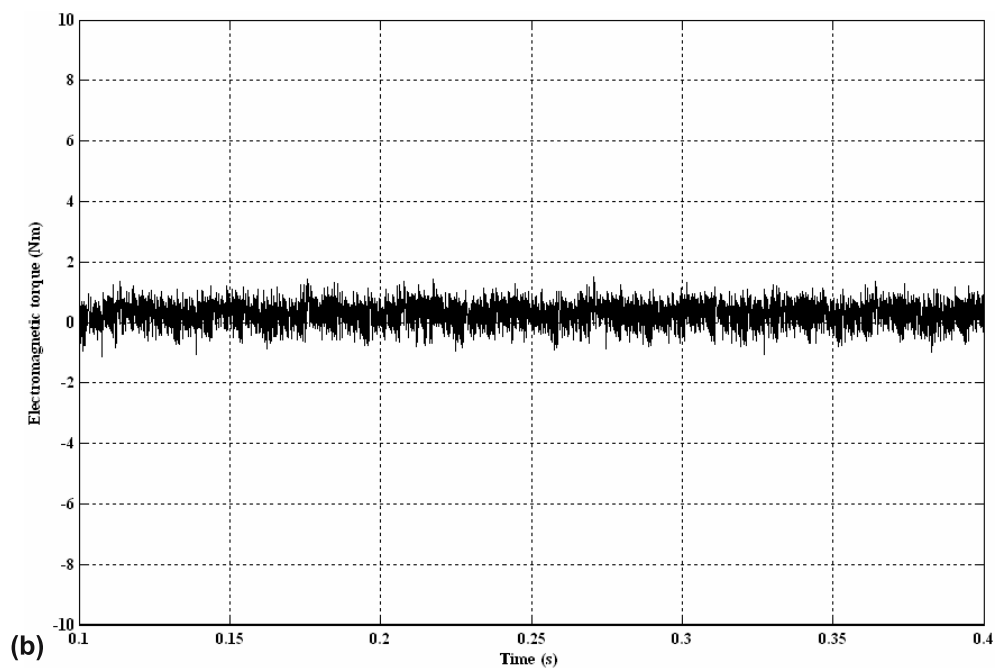

Figure 8b. Electromagnetic torque with dither injection. 


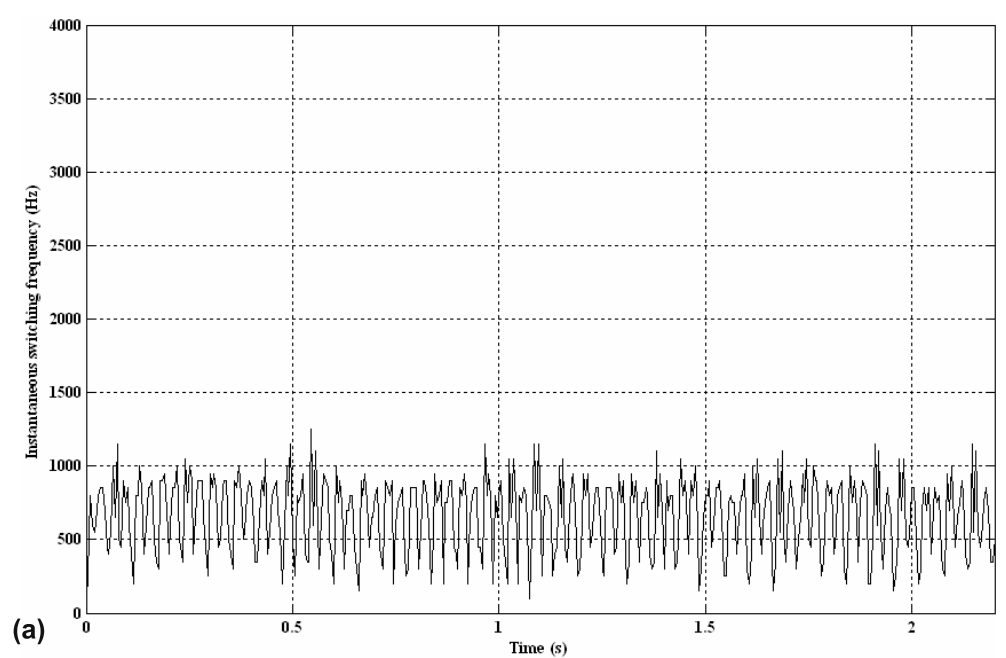

Figure 9a. Instantaneous switching frequency without dither signal.

IGBTs with feedback diodes are used as clamping diode to match the characteristics of the IGBT module. The rectifier is connected to capacitors and each capacitor rating is $2200 \mu \mathrm{F}$, $400 \mathrm{~V}$ DC.

The DTC drive along with all its components are implemented by using a DSP based DS1104 PCI dSPACE board. Induction motor ratings and parameters are given in table 2. Triangular dither is obtained using repetitive block of Matlab-Simulink. For experimental set-up this triangular signal is generated by the DSP.

Figures $10 \mathrm{a}$ and $\mathrm{b}$ show the torque and speed profile without and with triangular dither injections respectively. The electromagnetic torque is measured using system model. From

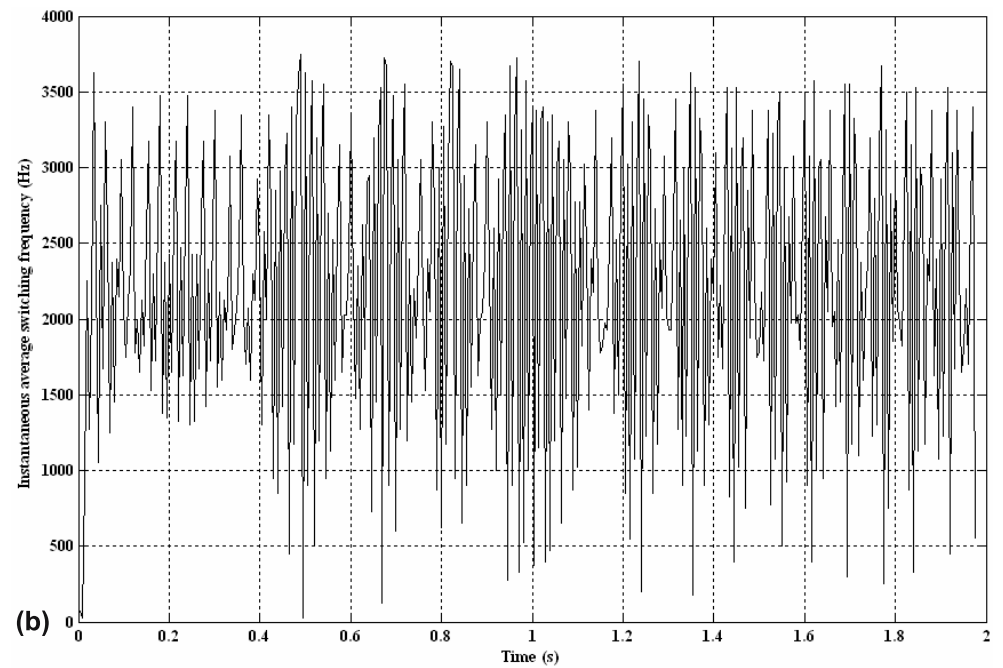

Figure 9b. Instantaneous switching frequency with triangular dither signal of $30 \mathrm{kHz}$. 


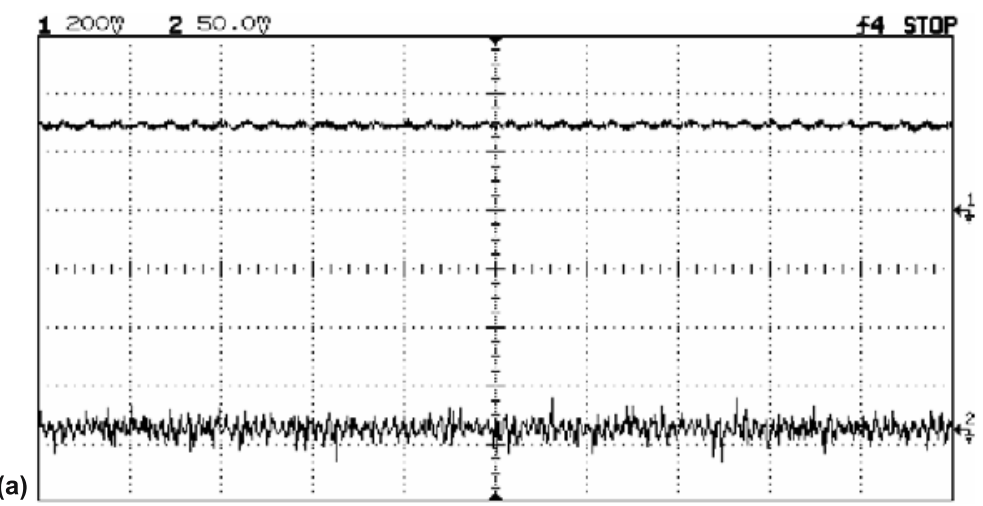

Figure 10a. Speed and electromagnetic torque when dither is not applied. Ref: 1: Speed: $500 \mathrm{rpm} / \mathrm{div}$; Ref: 2: Electromagnetic torque: $0.5 \mathrm{~N}-\mathrm{m} / \mathrm{div}$.

(b)

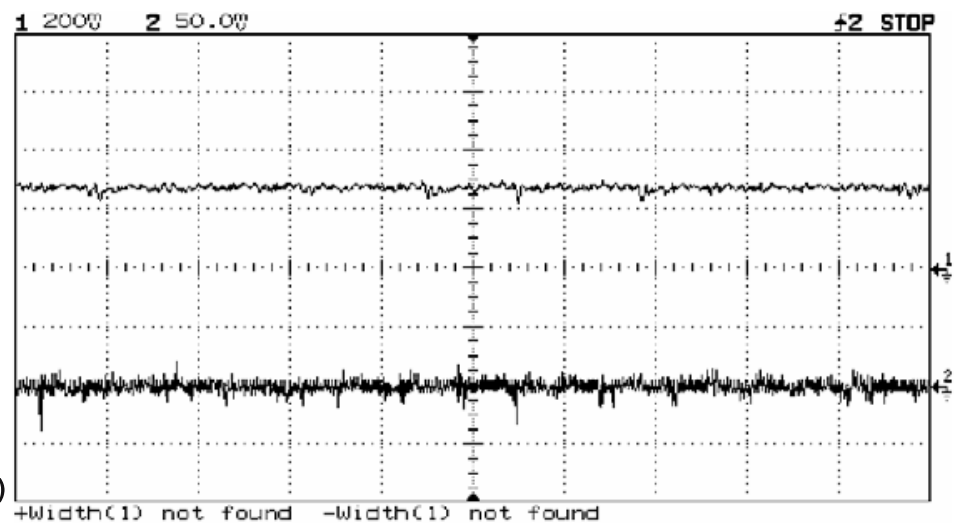

Figure 10b. Speed and electromagnetic torque when dither is applied. Ref: 1: Speed: $500 \mathrm{rpm} / \mathrm{div}$; Ref: 2: Electromagnetic torque: $0 \cdot 5 \mathrm{~N}-\mathrm{m} / \mathrm{div}$.

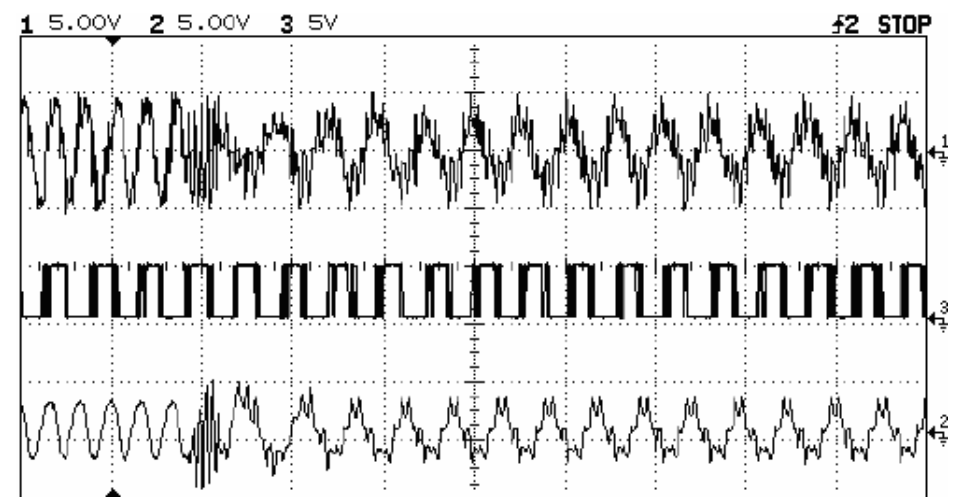

Figure 11. Transition from dither injection to without dither injection. Ref: 1: Line-to-line stator voltage; Ref: 2: Stator current (5 A/div); Ref: 3: Switching pulse. 
(a)

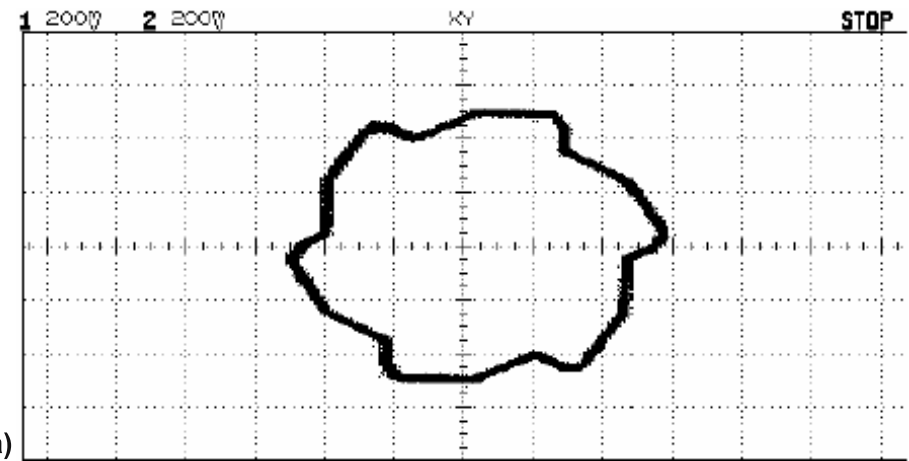

Figure 12a. Steady state stator $d-q$ axis flux locus without dither injection.

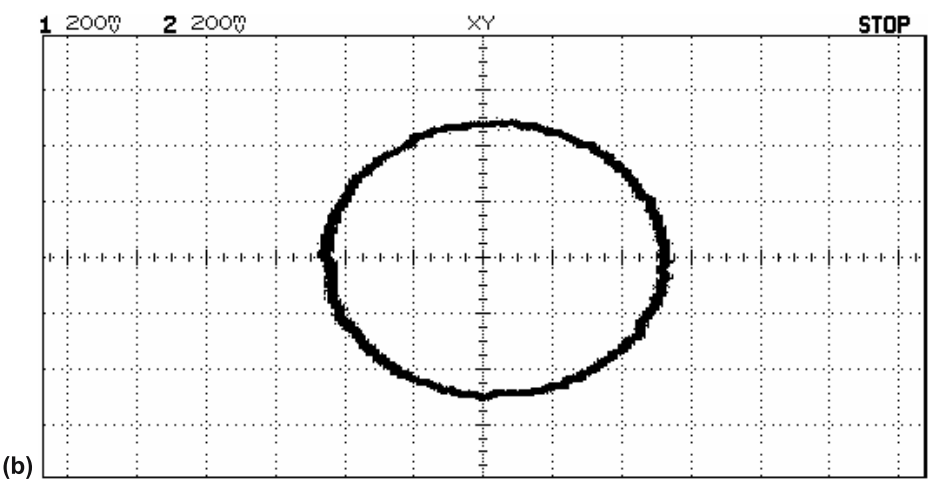

Figure 12b. Steady state stator $d-q$ axis flux locus with triangular dither injection.

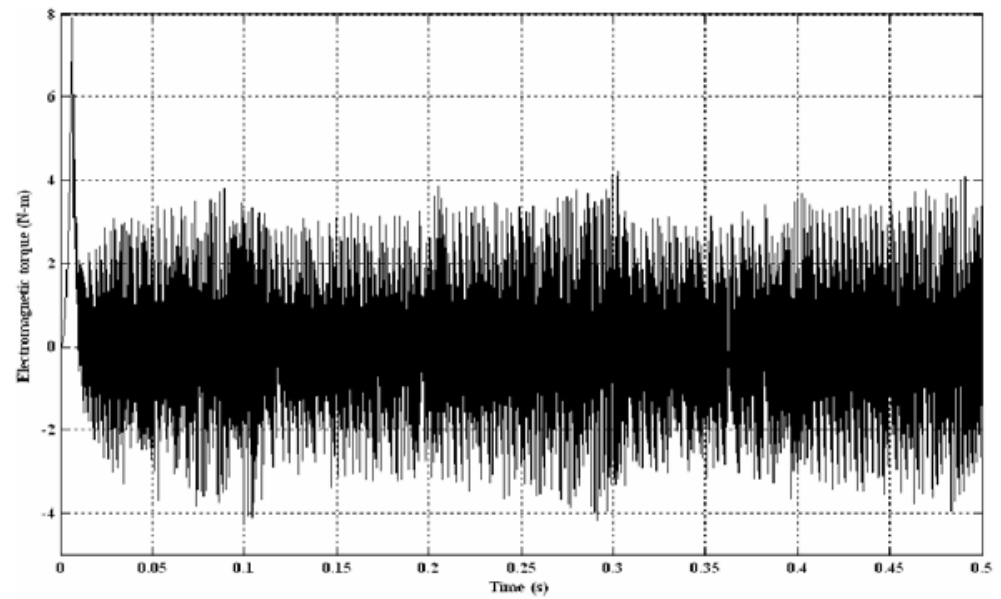

Figure 13. Electromagnetic torque when dither is not applied and induction motor is operating at low speed. 


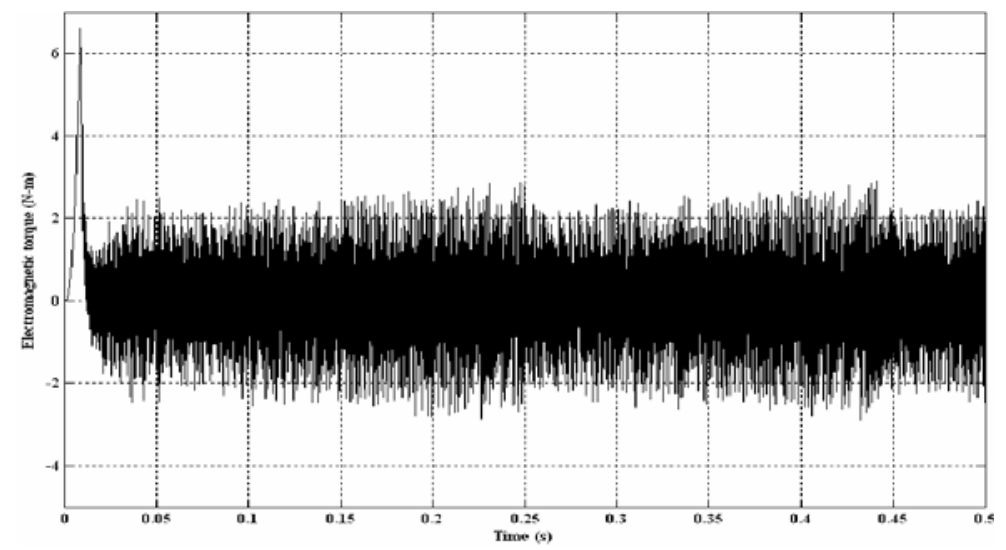

Figure 14. Electromagnetic torque when dither is applied and induction motor is operating at low speed.

the above-mentioned figures, it is observed that the torque ripple and speed fluctuations are minimized using dither injection.

In the DTC scheme given in figure 1, dither signal is applied for 4 seconds, and then the dither signal is removed. The resultant experimental result is given in figure 11. Figures 12a and $\mathrm{b}$ show the stator flux trajectory without dither and with triangular dither injection. It is observed that the flux ripple is also reduced using dither signal injection. In classical DTC methods, torque ripples are normally pronounced under starting and low speed conditions. Dither injection also improves the low speed performance of the DTC IM drive. When the induction motor is running at $50 \mathrm{rpm}$ without dither injection, the electromagnetic torque ripple increases as shown in figure 13. However, by injecting triangular dither signal the torque ripple is reduced and it is confirmed from simulation result given in figure 14.

\section{Conclusion}

An improved direct torque control (DTC) for induction motor drive with dither injection in hysteresis control loop was reported. The injection of dither signals increased the switching frequency of the inverter. This reduced current, flux and torque ripples. However, it retained the same dynamic response of torque and speed, and improved the switching frequency of inverter. It was observed in the simulation study that the torque ripple was reduced by $60 \%$ (peakto-peak) with dither injection. Matlab-Simulink based simulation results and experimental results from a laboratory prototype were presented to validate the control scheme.

\section{References}

Ambroži č V, Buja G S, Menis R 2004 Band-constrained technique for direct torque control of induction motor. IEEE Trans. Ind. Electronics 51(4): 776-784

Behera R K, Das S P 2006 A utility friendly high power induction motor drive with direct torque and flux control. In Proc. of IEEE International Conference on Industrial Technology 2006 1983-1988 Cook P A 1986 Nonlinear dynamical systems (Englewood Cliffs, NJ: Prentice-Hall)

Elgerd O I 1967 Control systems theory (New York: McGraw-Hill) 
Gelb A, Vander Veido W E 1968 Multiple-input describing function and nonlinear system design (New York: McGraw-Hill)

Iannelli L, Johansson K H, Jönsson U T, Vasca F 2003 Dither for smoothing relay feedback systems. IEEE Trans. on Circuits and Systems-I: Fundamental Theory and Applications 50(8): 1025-1035

Iannelli L, Vasca F 2004 Dither for chattering reduction in sliding mode control systems. In Proc. of ISCAS'04 4: 709-912

Kinkaid N M, Rom O, Papadopoulos P 2002 Automotive disc brake squeal: A review. J. Sound and Vib. 54-59

Noguchi T, Yamamoto M, Kondo S, Takahashi I 1999 Enlarging switching frequency in direct torque controlled inverter by means of dithering. IEEE Trans. Ind. Appl. 35(6): 1358-1366

Zames G, Shneydor N A 1976 Dither in nonlinear systems. IEEE Trans. Automatic Control AC-21(5): 660-667 